\title{
Menstrual Justice: A Missing Element in India's Health Policies
}

\author{
Swatija Manorama and Radhika Desai
}

\section{Introduction: A Menstrual Justice Framework}

Menstruation is a key process in a woman's life integral to her well-being and an indicator of her fertility. One expects that menstruation's contribution to the propagation of the species would lead to the valorization of both deed and doer-namely, menstruation and women. ${ }^{1}$ Instead, globally, and in particular in India (our site of research), menstruation is largely shamed and silenced. In India, the demarcation of female bodies as menstruating bodies is embedded deeply within religious, social, cultural, and political milieu and is customarily stigmatizing (Outlook 2018; Bhartiya 2013; Johnston-Robledo and Chrisler 2011). Against this background, our chapter explores how Indian health and related policies address menstruation and menstrual health.

Within Hinduism there are two contradictory streams of belief regarding menstruation. While menstrual blood and menstruating women are seen as 'polluting' because all bodily excretions are "ritually impure" (Bhartiya 2013, 524-25; Eichinger Ferro-Luzzi 1974; Garg and Anand 2015, $184-$ $86)$, the alternative 'tantric' view is that, through their menses, menstruating women embody infinite creative power and immense energy (Chawla 2002; Zsigmond 2012). The onset of menarche signifies fertility and is celebrated within many Hindu homes (Bhartiya 2013, 525; Eichinger Ferro-Luzzi 1974). For girls themselves, menarche signals the transition from childhood into the gendered construction of 'womanhood' (Manorama and Hora 2002). Girls recognize that the imposition of cultural and social controls over their pubescent bodies, their sexual and nonsexual deployment, and the manifold

Both authors have contributed equally to this work.

(C) The Author(s) 2020

C. Bobel et al. (eds.), The Palgrave Handbook of Critical Menstruation

Studies, https://doi.org/10.1007/978-981-15-0614-7_39 
increased restrictions on their physical mobility in time and space ensure that they grow to be 'women of a specific deportment' (Kågesten et al. 2016, 2; Manorama and Hora 2002).

We argue that the state, rather than confronting this complex web of beliefs and practices centered on menstruation, chooses to endorse it. Most recently, the state support for continued exclusion of women of menstruating age from the Sabarimala temple (Outlook 2018) is the most egregious instance of the state's role in the perpetuation of menstrual stigma. To signal the critical role of menstruation in the denial of gender justice, we propose a 'menstrual justice' $^{2}$ approach. Emerging from India's women's health and people's health movements (Manorama and Shah 1996; Saheli Women's Resource Centre 2001), this approach is based on an alternative understanding of women's biology and health. 'Menstrual justice' is a holistic approach that entails listening with sensitivity and respect to girls' and women's menstrual health needs that emerge from their sociocultural location and gendered everyday experiences (SAMA Team 2005; Rishyasyringa 2000).

The central tenet of the menstrual justice approach is that menstruation is a physiological process directly linked to psychosocial and cultural-religious aspects. Its objective is twofold: First, it seeks to make explicit all aspects of women's lives that are linked to menstruation beyond fertility and reproduction. Second, it helps to delineate the links between this complex web of thought and practices and women's experiences of indignity, discrimination, inequality, and injustice. It considers the specific ways in which the sociocultural-religious discourse of menstruation and its associated practices are reflected in national policies that effect violations of women's human rights, discrimination, and inequality. In doing so, the approach directs attention to the role of the political institutions and state policies in this process. Following an overview of the interconnections between menstruation and women's health, we examine state policies with reference to women's basic, psychosocial, gynecological, reproductive, and menopausal health in the context of the menstrual justice framework.

\section{An Overview of Interconnections Between the Menstrual Cycle and Health}

Anchoring of the menstrual justice framework in meanings associated with a bodily process makes it particularly suited to address gaps in women's health. We begin with a brief overview of the impacts of women's health and social factors on the menstrual cycle, demonstrating the need for policy and programming that recognizes and values the full spectrum of menstruality among women throughout India's diverse communities. 


\section{Basic Health}

Basic physical and psychosocial health are crucially tied to healthy childhood development, puberty, and the onset of menarche, as well as a predisposition to menstrual health-related morbidities and mortality throughout adulthood (UNICEF 2012; Biro and Deardorff 2013; Boutot 2018). Nutritional deficiencies affect the onset of menarche and menopause, intensity of PMS symptoms, and the duration, heaviness, and frequency of one's flow (Jeejebhoy 2000; Gokhale 1996; Patle et al. 2015; Jahangir 2018; Jungari and Chauhan 2017).

Girl-children encounter unequal access to the nutritional, medical, and emotional support systems essential to basic health (Guilmoto et al. 2018; Inamdar, Inamdar, and Sachdeva 2011). Early childhood malnutrition is the leading risk factor for disease nationwide and follows girls into adolescence and adulthood (India State-Level Disease Burden Initiative Collaborators 2017 , 2446). Approximately $38 \%$ girls under five are stunted, $21 \%$ are wasted, and $36 \%$ are underweight (Indian Institute of Population Studies (IIPS) and ICF 2017). In the age group $15-19,47 \%$ are underweight (UNICEF 2012), compared to $22.9 \%$ in the age group $15-49$. Anemia is a little over $50 \%$ in both groups (Indian Institute of Population Studies (IIPS) and ICF 2017; UNICEF, n.d.). Given their scale, these nutritional imbalances have a significant impact on menstrual health, as poor nutrition can delay menarche and disrupt the menstrual cycle.

\section{Psychosocial Health}

Discrimination against the girl-child leads to the 'normalization' of malnourishment, physical abuse and a sense of powerlessness and low self-esteem among preadolescent and early adolescent girls (Manorama and Hora 2002). Indian adolescent girls already tend to experience lower self-esteem and self-confidence, diffidence, and feelings of subordination compared to boys (Karki and Espinosa 2018, 113; Manorama and Hora 2002). Their branding as 'impure' after the onset of menarche undermines the healthy development of self-confidence and emotional well-being (Bharatwaj and Sindu 2014; Kumar and Srivastava 2011; Soumya and Sequira 2016, 12). Their lack of body and menstrual literacy and knowledge affirms and amplifies the negativity toward menstruation (FSG 2016; Raut et al. 2015, 63).

Additional social control at this critical developmental juncture is one more blow to the adolescent girl's fragile psychosocial state (Blum, Mmari, and Moreau 2017). Worldwide, depression is a common consequence of these restrictions (Chandra-Mouli et al. 2017, S6). In India, psychosocial problems are a more likely cause of suicides than diagnosable psychiatric problems (Mythri and Ebenezer 2016, 493-98), and 56\% of suicides of women occurred in the age group of 15-29, compared to $40 \%$ for men (Rane and Nadkarni 2014, 77). 


\section{Gynecological and Reproductive Care}

Under sociocultural silence and shame and misconceptions of what constitutes a 'normal' period, Indian women often refrain from reporting symptoms associated with gynecological morbidities; they consider symptoms such as severe pain to be part and parcel of being women (Inamdar, Sahu, and Doibale 2013, 9; Ramasubban and Jeejebhoy 2000a, 24-25). Reproductive Tract Infections (RTIs) and menstrual disorders are among the most commonly observed gynecological morbidities (Gosalia et al. 2012; Gulati, Chaurasia, and Singh 2009; Inamdar, Sahu, and Daibole 2013; Oomman 2000) and show increased incidence in older women, poor women, women with lower literacy, married women, and women with higher gravidity and parity (Tulasi and Babu 2018, 6; Oomman $2000,251-52$ ). Early age at menarche has been associated with gynecological morbidities as well (Das et al. 2015, 12; Oomman 2000, 250-51).

\section{Menopause}

India's mean age for the onset of menopause ranges between 41.9 and 49.4 years - significantly lower than the global mean of 45 to 55 (Pallikadavath et al. 2016, 367). Poor nutrition, lower socioeconomic status such as membership in a scheduled caste or tribe, adolescent pregnancy, lack of education, and exposure to strenuous work have been found to contribute to a higher prevalence of early menopause (Ahuja 2016; Jungari and Chauhan 2017; Syamala 2010, 254-55).

A high percentage of perimenopausal and postmenopausal women suffer from gynecological morbidities such as vaginal irritation, incontinence, reduced sexual desire, and mental health issues such as depression (Mishra 2011; Susila and Roy 2014, 55; Syamala 2010, 255). The symptoms are compounded by a burden of noncommunicable disease in the Indian population (Ahuja 2016; Susila and Roy 2014, 55). Despite these preliminary findings, studies of gynecological morbidity among menopausal women are rare.

The above discussion reveals high levels of ill-health among females from birth to old age that can be tied to menstrual health and body awareness. Across the life course, girls, women of reproductive age, perimenopausal, menopausal, and postmenopausal women exhibit a low level of basic and psychosocial health and a high incidence of gynecological morbidities, including menstrual health issues. In the next section, we examine India's national health policies to assess the manner in which the state has addressed these widespread basic and menstrual health problems.

\section{Analysis of Health Policies: A Menstrual Justice Perspective}

While our analysis focuses on health policies, we also include interrelated policies in adjacent sectors such as nutrition and sanitation. This section analyzes the policies introduced above: primary healthcare, psychosocial health, 
reproductive health and fertility control, and menopause. We also examine how menstrual health is addressed in sanitation policies.

\section{Primary Healthcare}

Until the formulation of India's National Health Policy (NHP) in 1983, healthcare was addressed through Five-Year Plans. The NHP 1983 endorsed the idea of "universal primary healthcare services" but rejected its concomitant goal of "free healthcare provision" on the grounds of unaffordability (Ministry of Health and Family Welfare, Government of India (MoHFWGOI) 1983). The NHP 1983 emphasized the curative approach at the expense of preventive, promotive public health, and rehabilitative aspects of healthcare (Duggal and Gangolli 2005). The NHP 1983 led to the expansion of health infrastructure (Duggal 2005, 33-34), but its expected benefits to women's health did not materialize. Health workers were not trained to cater to women's needs, and family planning and immunization took a disproportionate amount of their time (Duggal 2005, 34).

The NHP 2002 (MoHFWGOI 2002) moved away from the goal of universal comprehensive primary healthcare to a regime of public health characterized by selective care targeted at specific groups (Duggal 2005, 35). Recognizing women's poor health status (Sarojini et al. 2006, 23) and the withering of rural health capacity except for "family welfare activities" (MoHFWGOI 2002, 9), the NHP 2002 promised "top funding priority to programmes relating to women's health" (Sarojini et al. 2006, 23; MoHFWGOI 2002, 32). However, health benefits still did not accrue because the policy's approach to women's health lacked specificity (Sarojini et al. 2006, 24). While it mentioned the need to "attend to specific requirements of women in a more comprehensive manner" (MoHFWGOI 2002,32 ), it did not identify a single women's health issue. The only women-specific goal it set was to reduce the Maternal Mortality Rate (MMR), revealing its reductive understanding of women's health as maternal health (MoHFWGOI 2002, 21).

The policy prescriptions of the NHP 2002-namely, improvement in availability and access to quality healthcare for rural populations, especially women and children-were reflected in National Rural Health Mission (NRHM) 2005 (MoHFWGOI 2015). In reality, programs of reproductive and child health and HIV/AIDS in NRHM 2005 got greater funding support over primary healthcare (Duggal and Gangolli 2005, 11). The Accredited Social Health Activists (ASHA), introduced as an interface between the village and the public health system, were given insufficient training for primary and menstrual healthcare functions, and their incentive structure was aligned to promote reproductive health and family planning (Sarin et al. 2016; Hussain $2011,56)$.

Women's health was also purportedly targeted through national nutrition interventions, which can have a significant impact on improving menstrual 
health. These include the Integrated Child Development Services Scheme introduced in 1975 and the Nutrition Policy of 1993. The scheme initially provided nutrition supplements only to undernourished pregnant women, lactating mothers, and children under age six (Ministry of Women and Child Development, Government of India (MoWCDGOI) 1975). The Nutrition Policy of 1993 (MoWCDGOI 1993) extended nutritional support to malnourished adolescent girls to redress high levels of undernourishment (Kanani 2002). However, the policy did not propose a plan to address intrahousehold gender discrimination toward girl-children such as underfeeding, little or no provision of nutritional foods, denial of medical treatment for ill-health, et cetera, which is the primary cause of malnourishment. The policy lacked a perspective of "women's nutrition for its own sake" (Kanani 2002) and continued to adopt the myopic view of equating women's health with reproduction. It failed to suggest measures to compensate the specific nutritional shortfalls of menstruating or menopausal women and to institute a research program to examine the impact of malnourishment on women's menstrual health across the life cycle (Jeejebhoy 2000, 145; Oomman 2000, 260; Sandoiu 2017).

The most recent National Health Policy (2017) does not address the gaps in the provision of healthcare to women either (MoHFWGOI 2017), although it has a sprinkling of 'women's health issues' across its 30-odd pages. Women's health needs are specifically addressed in the sections on reproductive health, maternal health, child and adolescent health $(\mathrm{RMNCH}+\mathrm{A})$, malnutrition, population stabilization, gender-based violence (GBV), and women's health and gender mainstreaming. Under the subheading of "Women's Health \& Gender mainstreaming" it mentions "enhanced provisioning for reproductive morbidities and health needs of women beyond the reproductive age group $(40+)$ " (MoHFWGOI 2017, 14); however, there is no mention of how this is to be achieved through changes in the current health programs.

The trajectory of India's national health and nutrition policies shows encouraging growth in awareness of the need to rectify gender imbalances and to devote more resources toward improving women's health. However, we do not yet see sufficient programmatic changes to support the implementation of these policies.

\section{Psychosocial Health}

India's first National Mental Health Policy, adopted in 2014, mentions in its preamble the necessity to cater to vulnerable groups (MoHFWGOI 2014). Yet it fails to address the mental health consequence of high levels of stress women suffer because of gender discriminatory practices such as neglect, child marriage, infertility, failure to give birth to sons, witch-hunting, and sexual assault within marriage (Ramasubban and Jeejebhoy 2000a, 34; Sarojini et al. 2006, 41). The policy also seems blind to the emotional anguish women suffer because of 
chronic issues related to menstruation and the impact of other diseases on menstruation (Oomman 2000, 253-55; Alvergne, Wheeler, and Tabor 2018). For instance, it fails to recognize the negative psychosocial health impacts of the perception that girls and women are 'polluting' during menstruation (FSG 2016). Rather than mandate access to counselors and health workers equipped with gender-sensitive training on menstrual health as demanded by women's health activists (Oomman 2000, 257-58), the policy medicalizes mental health conditions in psychiatric terms and adopts a 'special case' approach that does not cater to the mental health of menstruating women (Varma 2014, 45).

\section{Reproductive Healthcare and Fertility Control}

Population growth led to the integration of Family Planning Program (FPP) and health services since the Third Five-Year Plan (1961-1966) (Ministry of Health and Family Welfare, Government of India (MoHFWGOI) 2000; Visaria 2000, 335). FPP is part of a primary healthcare system whose beneficiaries were illiterate, poor, and 'lower' caste women. Women were provided contraceptives with little regard for their needs, and the quality of services was poor (Visaria 2000). The result was an increase in menstrual problems and RTIs from intrauterine devices and gynecological morbidities post-sterilization (Oomman 2000, 247-48). It was only in 1997 that the government accepted a women's empowerment and comprehensive reproductive healthcare paradigm through its Reproductive and Child Health $(\mathrm{RCH})$ program. The $\mathrm{RCH}$ included some services demanded by women activists: prevention and treatment of RTIs and sexually transmitted infections (STIs); reproductive health services for adolescents; and information, education, and counseling on health, sexuality, and gender (Sarojini et al. 2006, 28). But the government's own review of $\mathrm{RCH}$ showed that critical components of reproductive and sexual health were ignored in training and implementation, resulting in a lack of treatment for contraceptive side effects and post-delivery complications. There was also a total neglect of health needs of adolescents outside marriage (Santhya 2003, 28; Sarojini et al. 2006, 31). Failure to address critical factors of the $\mathrm{RCH}$ approach - such as the right to information on associated risks and the unavailability of services or skilled personnel to deal with side effects of contraception-led to exacerbating women's already poor health, including gynecological morbidities (Pachauri 2004, 18; Santhya 2003, 25-26).

Even in programs to prevent STIs, menstrual and gynecological care was not given precedence (WHO 2007, 2). There were no processes to empower women and enable them to choose their contraceptive methods or treatments for infection (SAMA Team 2005, 157; Santhya 2003, 28). The subsequent phases of RCH- RCH II (2005) and Reproductive, Maternal and Child Health, Plus Adolescents (RMNCHA+) (2013) - have made no midcourse corrections; instead, they've shifted the focus once again to maternal, infant, and child care (Ministry of Health and Family Welfare, Government of India (MoHFWGOI), n.d.). The implementation of $\mathrm{RCH}$ shows an absence of 
promotion of adolescent and adult women's knowledge of their own bodies, issues of sexuality, menstrual health and hygiene, and the right to contraceptive choice without coercion. The above overview of reproductive health policies demonstrates that population control continues to be bundled within reproductive health and is least concerned with menstrual health. The RCH program does not recognize the continuities between reproductive health, general health, and women's social location.

\section{Menopause}

The NHP 2017 recognizes the health needs of women beyond reproductive age $(40+)$ (MoHFWGOI 2017). As such, it has taken the first steps toward heeding the demands of women's health activists for policies that address women's health across the life cycle rather than merely in their reproductive years (SAMA Team 2005). However, the policy homogenizes older women; it includes women in late reproductive age, perimenopausal, recently postmenopausal, and beyond age 60, and it does not give any indication of the strategy to address health issues of this $40+$ age group. The health needs of this group are also covered in the 1999 National Policy on Older Persons, which was drastically revised in 2011. Like the NHP 2017, it shows awareness of the need for increased attention on older women, but its approach to issues of aging is gender-neutral (Ministry of Social Justice, Government of India 2011). Neither policy recognizes the consequences of menstrual conditions experienced before menopause and the ramifications of menopause on physical and mental health; neither articulates which treatments or procedures within existing infrastructure can be used to treat postmenopausal morbidities. Also missing is any recognition of the need for gender-specific research on issues such as detriments to women's postmenopausal longevity and long-term consequences of gynecological morbidities (ibid.; Syamala 2010; Jani and Manorama 2007).

An analysis of India's past policies on physical and mental health reveals historical approaches to women's health that are based on a myopic understanding of women as 'female reproducing bodies' who need to be managed for population stabilization and reproductive health. This limited focus has perpetuated neglect of the health needs of girl-children, prepubescent girls, and perimenopausal and postmenopausal women. It does nothing to interrupt and dismantle the cycles of menstrual stigma that compromise women's and girls' mental and physical health.

\section{Swachb Bharat Abhiyaan (SBA): The 'Clean India Mission'}

The SBA is the first large-scale government program that includes a strategy to bring out the taboo subject of menstruation (Swachh Bharat Mission 2019). This section briefly analyzes the component of menstrual hygiene management (MHM) in SBA through the lens of menstrual justice (see also Patkar 
[Chapter 38] in this volume). The goals of SBA are (1) achievement of dignity for adolescent girls and women and (2) retention of adolescent girls in school (FSG 2016) through a strategy of providing sanitation infrastructure, access to menstrual products, and information, education, and communications (IEC) for MHM awareness among adolescent school-going girls, boys, and community. The aim of IEC, per its technical guidelines, is "to create awareness in order to overcome the silence around MHM and break the taboos within the broader society, communities, and also among family members" (Ministry of Drinking Water and Sanitation, Government of India, n.d., 1). The IEC material is mandated to include:

Facts about menstruation, biology and process; Frequently-asked questions and answers; Myths about menstruation and address them with facts; Case studies/ experience from girls-How to stay healthy during menstruation-what protection to wear, what to eat, what exercise to take, how to keep clean, how to deal with cramps, how to clean, dry or dispose of sanitary materials, etc. (Ministry of Drinking Water and Sanitation, Government of India 2015, 13)

A close reading of the SBA guidelines for MHM shows two critical gaps, namely (1) absence of culturally embedded gender-specific understandings of menstruation and (2) linkages with public health. Both of these have consequences for girls' and women's menstrual health. Embodied shame, guilt, and negativity among Indian adolescent girls is not linked merely to the biology of menstruation but to the complex web of beliefs and practices of menstruation and its sociocultural and religious meanings that result in indignity and injustice. The onset of menarche is accompanied with increased disciplining on 'how to be a woman,' and adolescent girls' mental health and sense of self-esteem are negatively affected (FSG 2016; Garg and Anand 2015; Karki and Espinosa 2018). The SBA does not include any programmatic interventions to address these core gender-specific aspects of menstruating adolescent girls. As argued in a 2016 landscape analysis of menstrual health in India, "the lack of psycho-social support and limited facilitator capacities miss the opportunity to build the girl's confidence and shift inherent discriminatory social norms that define a girl's role in Indian society" (FSG 2016, 18). SBA's 'theory of change'- that awareness of menstruation as a natural physiological process will remove silence, stigma, and shame-is simplistic and grossly inadequate.

India's public health system has a vast infrastructure and network of workers at the village level-the site at which SBA is being implemented. One of the central features of any water, sanitation and hygiene (WASH) program is the connection to health. Yet the MHM Guidelines in SBA do not have any component to make visible the relationship of the menstrual cycle to basic health, psychosocial well-being, and menstrual health. The SBA envisions MHM in a restrictive manner, as an issue to be addressed only in the context of the period of bleeding, not across the menstrual cycle. Therefore, although its IEC 
material includes information on the biology of the menstrual cycle, it does not have any programmatic component to link adolescent girls with public health.

The SBA's shortsightedness missed an excellent opportunity to link the MHM and WASH agenda with the public health agenda in spite of the $\mathrm{RCH}$ focus on the public health system for over two decades. The focus on 'hygiene' rather than 'health' means a lost chance to address health issues associated with the disorders of the menstrual cycle, such as dysmenorrhea, amenorrhea, menorrhagia, pelvic infections, and endometriosis, among others. The SBA, currently housed in two separate ministries (the Ministry of Drinking Water and Sanitation and the Ministry of Housing and Urban Affairs), should have invited the Ministry of Health to colead the SBA or to build the missing components required for a comprehensive menstrual health approach through revisions of the NHP 2017. Instead the NHP 2017, formulated a full three years after the launch of the SBA, only includes a stated 'intention of introducing school health programs to address issues of health and hygiene' (MoHFWGOI 2017, 11), possibly a veiled reference to menstrual health and hygiene. The NHP 2017 too has failed to grasp the opportunity offered by SBA to incorporate discourse and action to address barriers to women's menstrual health.

\section{Conclusion}

India's health policies $(1983,2002$, and 2017) and adjacent policies on nutrition, mental health, older persons, population, and rural health have failed to address the inextricable linkage between menstrual stigma and women's basic health. The recent SBA is no exception, evident in the fact that it restricts its intervention to MHM and does not extend it to menstrual health.

We propose a new construct, 'menstrual justice,' to make explicit the links between the marking of women's bodies as inferior and the discrimination, inequality, and injustice they suffer. In particular, we oppose the use of menstruation to control women and their bodies, including the use of categories that compartmentalize women and girls: preadolescents and adolescents, women of reproductive age, and postmenopausal women. These artificial divisions ignore continuities in the underlying causes of women's experiences of ill-health across the life cycle. We contend that, in practice, women physically and psychosocially experience the health effects of having their bodies marked as 'impure' well before the bleeding begins and well after it ceases. Thus, we propose a nonreductionist approach to women's health that goes beyond the narrow confines of fertility and menstrual health: menstrual justice in health.

The menstrual justice framework provides a lens through which to comprehend the discrimination and human rights violations that are borne by women and that result from marking women primarily and exhaustively as 
'menstruating bodies' in the specific sociocultural and religious contexts of India. Rooted in women's rights and gender equality, this lens can serve as the basis for compelling the state to dismantle edifices built on the designation of menstruating Indian women's bodies as 'impure.'

\section{Notes}

1. We recognize that the term menstruators is more gender inclusive, and nonessentializing. However, our chapter focuses on discrimination against women embedded in India's partriachal society, so we opted to use the terms woman and women here. The complex processes of affirmation, challenge, and discrimination against individuals who identify as Third Gender in India are beyond the scope of this chapter.

2. Margaret Johnson (2019) captures the multiplicity of axes of domination that impact women's experiences of menstruation and suggests that Menstrual Justice is a 'structural intersectionality.' Our concept of Menstrual Justice has emerged from the bottom up, from Indian women's everyday experiences of menstruation in the sociocultural, religious, and political conditions of their living.

\section{REFERENCES}

Ahuja, Maninder. 2016. "Age of Menopause and Determinants of Menopause Age: A PAN India Survey by IMS." Journal of Midlife Health 7 (3): 126-31. https://doi. org/10.4103/0976-7800.191012.

Alvergne, Alexandra, Marija Vlajic Wheeler, and Vedrana Hogqvist Tabor. 2018. "Do Sexually Transmitted Infections Exacerbate Negative Premenstrual Symptoms? Insights from Health." Evolution, Medicine, and Public Health 2018: 138-50. https://doi.org/10.1093/emph/eoy018.

Bharatwaj, R. S., K. Vijaya, and T. Sindu. 2014. "Psychosocial Impact Related to Physiological Changes Preceding, at and Following Menarche among Adolescent Girls." International Journal of Clinical Surgical Advances 2 (1): 42-53.

Bhartiya, Aru. 2013. "Menstruation, Religion and Society." International Journal of Social Science and Humanity 3 (6): 523-27.

Biro, Frank, and Julianna Deardorff. 2013. "Identifying Opportunities for Cancer Prevention during Preadolescence and Adolescence: Puberty as a Window of Susceptibility." Journal of Adolescent Health 52: S15-S20. http://dx.doi. org/10.1016/j.jadohealth.2012.09.019.

Blum, Robert, Kristin Mmari, and Caroline Moreau. 2017. "It Begins at 10: How Gender Expectations Shape Early Adolescence Around the World." Journal of Adolescent Health 61: S3-S4. https://doi.org/10.1016/j.jadohealth.2017.07.009.

Boutot, Meagan. 2018. "The Immune System and the Menstrual Cycle." Clue, March 7. https://helloclue.com/articles/cycle-a-z/the-immune-system-and-themenstrual-cycle.

Chandra-Mouli, Venkatraman, Marina Plesons, Emmanuel Adebayo, Avni Amin, Michal Avni, Joan Marie Kraft, Catherine Lane, et al. 2017. "Implications of the Global Early Adolescent Study's Formative Research Findings for Action and for Research." Journal of Adolescent Health 61: S5-S9. 
Chawla, Janet. 2002. “Celebrating the Divine Female Principle.” Boloji, September 16. http://www.boloji.com/articles/6151/celebrating-the-divine-female-principle.

Das, Padma, Kelly Baker, Ambarish Dutta, Tapoja Swain, Sunita Sahoo, Bhabani Sankar Das, Bijay Panda, et al. 2015. "Menstrual Hygiene Practices, WASH Access and the Risk of Urogenital Infection in Women from Odisha, India.” PLoS One 10 (6): e0130777. https://doi.org/10.1371/journal.pone.0130777.

Duggal, Ravi. 2005. "Historical Review of Health Policy Making." In Review of Health Care in India, edited by Leena V. Gangolli, Ravi Duggal, and Abhay Shukla, 21-40. Mumbai: Center for Enquiry into Health and Allied Themes (CEHAT).

Duggal, Ravi, and Leena V. Gangolli. 2005. "Introduction to Review of Healthcare in India." In Review of Health Care in India, edited by Leena V. Gangolli, Ravi Duggal, and Abhay Shukla, 3-18. Mumbai: Center for Enquiry into Health and Allied Themes (CEHAT).

Eichinger Ferro-Luzzi, Gabriella. 1974. "Women's Pollution Periods in Tamil Nadu (India)." Anthropos Bd. 69 H. 1/2: 113-161. http://www.jstor.org/ stable/40458513.

FSG. 2016. "Menstrual Health in India-Country Landscape Analysis.” FSG. http:// menstrualhygieneday.org/wp-content/uploads/2016/04/FSG-Menstrual-HealthLandscape_India.pdf.

Garg, Suneela, and Tanu Anand. 2015. "Menstruation Related Myths in India: Strategies for Combating It." Journal of Family Medicine Primary Care 4, no. 2 (April-June): 184-86. https://doi.org/10.4103/2249-4863.154627.

Gokhale, Leela. 1996. “Curative Treatment of Primary (Spasmodic) Dysmenorrhoea.' The Indian Journal of Medical Research 103: 227-31. https://www.ncbi.nlm.nih. gov/pubmed/8935744.

Gosalia, Vibha, Pramodkumar Verma, Vikas Doshi, Manindrapratap Singh, Sanat Rathod, and Mehul Parmar. 2012. "Gynecological Morbidities in Women of Reproductive Age Group in Urban Slums of Bhavnagar City." National Journal of Community Medicine 3 (4): 657-60. http://www.njcmindia.org/home/ download/337.

Guilmoto, Christophe Z., Nandita Saikia, Vandana Tamrakar, and Jayanta Kumar Bora. 2018. "Excess Under-5 Female Mortality Across India: A Spatial Analysis Using 2011 Census Data." The Lancet Global Health 6 (6): e650-58. https://www. thelancet.com/pdfs/journals/langlo/PIIS2214-109X(18)30184-0.pdf.

Gulati, S. C., Alok R. Chaurasia, and Raghubansh M. Singh. 2009. "Women's Reproductive Morbidity and Treatment-Seeking Behaviour in India." Asian Population Studies 5 (1): 61-84. https://doi.org/10.1080/17441730902790131.

Hussain, Zakir. 2011. "Health of the National Rural Health Mission." Economic and Political Weekly of India 46 (4): 53-60.

Inamdar, I. F., C. Sahu Priyanka, and Doibale, M. K. 2013. "Gynaecological Morbidities among Ever Married Women: A Community Based Study in Nanded City, India." IOSR Journal of Dental and Medical Sciences (IOSR-JDMS) 7 (6): 5-11. www.iosrjournals.org.

Inamdar, Madhuri, Sameer Inamdar, and N. L. Sachdeva. 2011. "Health Status of Rural Girls." National Journal of Community Medicine 2 (3): 388-93. http://www. njcmindia.org/home/issue_download/2/3.

India State-Level Disease Burden Initiative Collaborators. 2017. "Nations Within a Nation: Variations in Epidemiological Transition Across the States of India, 1990-2016 in the Global Burden of Disease Study." Lancet 390: 2437-60. http://dx.doi.org/10.1016/. 
Indian Institute of Population Studies (IIPS) and ICF. 2017. "National Family Health Survey (NFHS-4), 2015-16: India.” Mumbai: IIPS. http://rchiips.org/Nfhs/ NFHS-4Reports/India.pdf.

Jahangir, Andisheh. 2018. "Do Nutritional Deficiencies Lead to Menstrual Irregularities?" International Journal of Nutritional Science and Food Technology 4, no. 5 (July): $27-31$.

Jani, Anju, and Swatija Manorama. 2007. "Ageing Women and Health Care Technologies, Public Health and Policies." Second National Bioethics Conference, Indian Journal of Medical Ethics, NIMHANS Convention Centre, Bangalore, India, December 6-8.

Jeejebhoy, Shireen. 2000. "Safe Motherhood in India: Priorities for Social Science Research." In Women's Reproductive Health in India, edited by Radhika Ramasubban and Shireen Jejeebhoy, 236-79. Jaipur: Rawat Publications.

Johnson, Margaret. 2019. "Menstrual Justice.” UC Davis Law Review 53 (1): 1-79.

Johnston-Robledo, Ingrid, and Joan C. Chrisler. 2011. "The Menstrual Mark: Menstruation as Social Stigma." Sex Roles, July 31. https://doi.org/10.1007/ s11199-011-0052-z.

Jungari, Suresh, and Bal Govind Chauhan. 2017. "Prevalence and Determinants of Premature Menopause among Indian Women: Issues and Challenges Ahead." Health \& Social Work 42 (2): 79-86. https://doi.org/10.1093/hsw/hlx010.

Kågesten, A., S. Gibbs, R. W. Blum, C. Moreau, V. Chandra-Mouli, A. Herbert, and Avni Amin. 2016. "Understanding Factors That Shape Gender Attitudes in Early Adolescence Globally: A Mixed-Methods Systematic Review.” PLoS One 11 (6): e0157805. https://doi.org/10.1371/journal.pone.0157805.

Kanani, Shubhada. 2002. "How Gender Sensitive Is the National Nutritional Policy of India?-A View of the Policy through the Gender Lens." Medico Friend Circle Bulletin (January-February): 292-93.

Karki, Richa, and Cristina Espinosa. 2018. "Breaking Taboos: Menstruation, Female Subordination and Reproductive Health, the Case of India." Insights Anthropology 2 (1): 111-20. https://scholarlypages.org/Articles/anthropology/iap-2-011. php?jid=anthropology.

Kumar, Anant, and Kamiya Srivastava. 2011. "Cultural and Social Practices Regarding Menstruation among Adolescent Girls." Social Work in Public Health 26: 594-604. https://doi.org/10.1080/19371918.2010.525144.

Manorama, Swatija, and Chayanika Shah. 1996. "Towards a New Perspective on Women's Bodies: Learning and Unlearning Together." Economic and Political Weekly 31 (16-17): WS-35-38. https://www.epw.in/journal/1996/16-17/ review-womens-studies-review-issues-specials/towards-new-perspective-womens.

Manorama, Swatija, and Nischint Hora. 2002. "Subterranean Violence in the City: Working with Pre-Adolescent Schoolgirls in Mumbai." Abstract of Paper presented at the Conference, "Gender and Culture: Leisure, Consumption and Women's Everyday Lives." Cheltenham and Gloucester, UK, 12-14 July 2001. Published at Women's Global Network for Reproductive Rights Newsletter 75-Atria. https://www. atria.nl/ezines/email/WomensGlobalNetwork/2002/No75.pdf.

Ministry of Drinking Water and Sanitation, Government of India (MoDWSGOI). 2015. "Menstrual Hygiene Management-National Guidelines.” Accessed July 16, 2018. https://jalshakti-ddws.gov.in/sites/default/files/Menstrual $\% 20$ Hygiene $\% 20$ Management\%20-\%20Guidelines_0.pdf. 
n.d. "Technical Guide 1. IEC for MHM.” Accessed July 16, 2018. http:// unicef.in/CkEditor/ck_Uploaded_Images/img_1512.pdf.

Ministry of Health and Family Welfare, Government of India (MoHFWGOI). 1983. "National Health Policy 1983." Accessed July 16, 2018. https://www.nhp.gov.in/ sites/default/files/pdf/nhp_1983.pdf.

- 2000. "National Population Policy 2000." Department of Family Welfare, Ministry of Health and Family Welfare, Government of India. Reprint 2002. https://mohfw.gov.in/sites/default/files/26953755641410949469\%20\%281\%29. pdf.

. 2002. "National Health Policy 2002." Ministry of Health and Family Welfare, Government of India. Accessed July 16, 2018. https://mohfw.gov.in/sites/ default/files/18048892912105179110National.pdf.

—. 2014. "New Pathways New Hope." National Mental Health Policy of India. October 2014. https://www.nhp.gov.in/sites/default/files/pdf/national\%20 mental\%20health\%20policy\%20of\%20india\%202014.pdf.

—. 2015. "National Rural Health Mission 2005." Accessed July 16, 2018. https://www.nhp.gov.in/the-national-rural-health-mission_pg.

- 2017. "National Health Policy 2017." Ministry of Health and Family Welfare, Government of India. Posted April 28, 2017. https://mohfw.gov.in/sites/default/ files/9147562941489753121.pdf.

—. n.d. "National Health Mission." https://nhm.gov.in/indexl.php?lang= 1 \&level $=1$ \&sublinkid $=794 \&$ lid $=168$.

Ministry of Social Justice. Government of India (MoSJGOI). 2011. "National Policy for Senior Citizens." March 2011. http://socialjustice.nic.in/writereaddata/ UploadFile/dnpsc.pdf.

Ministry of Women and Child Development, Government of India. 1975. "Integrated Child Development Services (ICDS) Scheme.” Accessed July 16, 2018. https:// icds-wcd.nic.in/icds.aspx.

Ministry of Women and Child Development, Government of India (MoWCDGOI). 1993. "Nutrition Policy 1993." Accessed July 16, 2018. https://wcd.nic.in/sites/ default/files/nnp_0.pdf.

Mishra, Shailendra Kumar. 2011. "Menopausal Transition and Postmenopausal Health Problems: A Review on Its Bio-cultural Perspectives." Health 3 (4): 233-37. https://doi.org/10.4236/health.2011.34041.

Mythri, Starlin, and Johann Ebenezer. 2016. "Suicide in India: Distinct Epidemiological Patterns and Implications." National Guidelines MHM. Accessed July 16, 2018. https://jalshakti-ddws.gov.in/sites/default/files/Menstrual\%20Hygiene $\% 20$ Management\%20-\%20Guidelines_0.pdf.

Oomman, Nandini. 2000. "A Decade of Research on Reproductive Tract Infections and Other Gynaecological Morbidity in India: What We Know and What We Don't Know." In Women's Reproductive Health in India, edited by Radhika Ramasubban and Shireen Jejeebhoy, 236-79. Jaipur: Rawat Publications.

Outlook. 2018. "Editor's Essay: Why Menstruation Is Outlook's Issue of the Year." December 27. https://www.outlookindia.com/magazine/story/issue-of-the-yearmenstruation-why-it-was-the-natural-choice/301037.

Pachauri, Saroj. 2004. "Expanding Contraceptive Choice in India: Issues and Evidence." The Journal of Family Welfare 50 (Special Issue): 13-25. 
Pallikadavath, S., R. Ogollah, A. Singh, T. Dean, A. Dewey, and W. Stones. 2016. "Natural Menopause among Women Below 50 Years in India: A Population-Based Study." The Indian Journal of Medical Research 144 (3): 366-77. https://doi. org/10.4103/0971-5916.198676.

Patle, A. Rupali, and Sanjay S. Kubde. 2015. "Anemia: Does It Have Effect on Menstruation?" Scholars Journal of Applied Medical Sciences 3 (1G): 514-17. https:// pdfs.semanticscholar.org/5cbc/6c989933a25419bbb4la63f332715f866abf.pdf.

Ramasubban, Radhika, and Shireen J. Jeejebhoy. 2000a. "Introduction." In Women's Reproductive Health in India, edited by Radhika Ramasubban and Shireen Jejeebhoy, 13-39. Jaipur: Rawat Publications.

- eds. 2000b. Women's Reproductive Health in India. Jaipur: Rawat Publications.

Rane, Anil, and Abhijit Nadkarni. 2014. "Suicide in India: A Systematic Review." Shanghai Archives of Psychiatry 26 (2): 69-80. http://dx.doi.org/10.3969/j. issn.1002-0829.2014.02.003.

Raut, Prerana, V. V. Wagh, S. G. Choudhari, and A. B. Mudey. 2015. "Need for Counseling Services to Get Rid of Negativity Linked with Menstruation-A Study among Late Adolescent Rural Girls in Central India." International Journal of Health Sciences \& Research 60 (5): 60-65.

Rishyasyringa, Bhanwar. 2000. "Social Policy and Reproductive Health." In Women's Reproductive Health in India, edited by Radhika Ramasubban and Shireen J. Jejeebhoy, 418-45. Jaipur: Rawat Publications.

Saheli Women's Resource Centre. 2001. "Reproductive Rights in the Indian Context: An Introduction." English Version of chapter, In Nariwadi RajaneetiSangharshaevam Mudde (Feminist Strategies-Struggles and Issues), edited by Sadhana Arya, Nivedita Menon, and Jinee Lokaneeta. Delhi: Delhi University.

SAMA Team. 2005. "Reproductive Health Services-The Transition from Policy Discourse to Implementation." In Review of Health Care in India, edited by Leena V. Gangolli, Ravi Duggal, and Abhay Shukla, 153-69. Mumbai: Center for Enquiry into Health and Allied Themes (CEHAT).

Sandoiu, Ana. 2017. Being Underweight May Trigger Early Menopause. Medical News Today, October 26. Accessed July 25, 2019. https://www.medicalnewstoday.com/ articles/319865.php.

Santhya, K. G. 2003. Changing Family Planning Scenario in India: An Overview of Recent Evidence. New Delhi, India: Population Council.

Sarin, Enisha, Sarah Smith Lunsford, Ankur Sooden, Sanjay Rai, and Nigel Livesley. 2016. "The Mixed Nature of Incentives for Community Health Workers: Lessons from a Qualitative Study in Two Districts in India." Frontiers of Public Health 4: 38. https://doi.org/10.3389/fpubh.2016.00038.

Sarojini, N. B., Suchita Chakraborty, Deepa Venkatachalam, Saswati Bhattacharya, Anuj Kapilashrami, and Ranjan De. 2006. Women's Right to Health. New Delhi, India: National Human Rights Commission.

Soumya, Leena, and Leena Sequira. 2016. "A Descriptive Study about Cultural Practices about Menarche and Menstruation." Nitte University Journal of Health Science 6 (2): 10-13.

Susila, T., and G. Roy. 2014. "Gynecological Morbidities in a Population of Rural Postmenopausal Women in Pondicherry: Uncovering the Hidden Base of the Iceberg." The Journal of Obstetrics and Gynecology of India 64 (1): 53-58. https:// doi.org/10.1007/s13224-013-0475-2. 
Swachh Bharat Mission-Gramin, Dept. of Drinking Water and Sanitation. Ministry of Jal Shakti 2019. "About SBM.” Last Modified March 12, 2019. http://swachhbharatmission.gov.in/SBMCMS/about-us.htm.

Syamala, T. S. 2010. "Reaching the Unreached: Older Women and the RCH Programme in India, the Challenges Ahead." Journal of Health Management 12 (3): 249-60. https://doi.org/10.1177/097206341001200303.

Tulasi, Naga P., and G. Krishna Babu. 2018. "Self Reported Gynaecological Morbidity among Currently Married Women in Urban Slums of Kakinada City, Andhra Pradesh." IOSR Journal of Dental and Medical Sciences (IOSR-JDMS) 17 (7): 4-7. https://doi.org/10.9790/0853-1707170407.

United Nations Children's Fund (UNICEF). 2012. "Progress for Children: A Report Card on Adolescents." Number 10, April 2012. http://www.unicef.org/media/ files/PFC2012_A_report_card_on_adolescents.pdf.

n.d. "Press Releases: Progress for Children." Accessed July 7, 2018. http:// unicef.in/PressReleases/61/Progress-for-Children-A-Report-Card-on-Adolescents.

Varma, Ruchika. 2014. “Absence of Women's Needs in the National Mental Health Programme of India." International Journal of Health Sciences 2 (1): 37-59. http://ijhsnet.com/journals/ijhs/Vol_2_No_1_March_2014/4.pdf, https://doi. org/10.15640/ijhs.

Visaria, Leela. 2000. "From Contraceptive Targets to Informed Choice: The Indian Experience." In Women's Reproductive Health in India, edited by Radhika Ramasubban and Shireen Jejeebhoy, 331-82. Jaipur: Rawat Publications.

World Health Organization (WHO), Regional Office for South-East Asia. (2007). "Adolescent Sexual and Reproductive Health \& HIV/AIDS among Young People: Compendium of Institutions in India". WHO Regional Office for South-East Asia. https://apps.who.int/iris/handle/10665/204767.

Zsigmond, André. 2012. "Ancient Tantric Goddess Worship-Past and Present." Goddess Pages Blog, April 17, 2012. Accessed May 20, 2018. https://www.goddess-pages.co.uk/blog/2012/04/17/ancient-tantric-goddess-worship-past-andpresent $-2 /$. 
Open Access This chapter is licensed under the terms of the Creative Commons Attribution 4.0 International License (http://creativecommons.org/licenses/ by/4.0/), which permits use, sharing, adaptation, distribution and reproduction in any medium or format, as long as you give appropriate credit to the original author(s) and the source, provide a link to the Creative Commons license and indicate if changes were made.

The images or other third party material in this chapter are included in the chapter's Creative Commons license, unless indicated otherwise in a credit line to the material. If material is not included in the chapter's Creative Commons license and your intended use is not permitted by statutory regulation or exceeds the permitted use, you will need to obtain permission directly from the copyright holder. 